\title{
Self-Concept in Kindergarten and First Grade Children: A Longitudinal Study on Structure, Development, and Relation to Achievement
}

\author{
Laura C. Dapp, Claudia M. Roebers \\ Institute of Psychology, University of Bern, Bern, Switzerland \\ Email: laura.dapp@psy.unibe.ch
}

How to cite this paper: Dapp, L. C., \& Roebers, C. M. (2018). Self-Concept in Kindergarten and First Grade Children: A Longitudinal Study on Structure, Development, and Relation to Achievement. Psychology, 9, 1605-1629.

https://doi.org/10.4236/psych.2018.97097

Received: May 19, 2018

Accepted: July 6, 2018

Published: July 9, 2018

Copyright ( 92018 by authors and Scientific Research Publishing Inc. This work is licensed under the Creative Commons Attribution International License (CC BY 4.0).

http://creativecommons.org/licenses/by/4.0/

(c) (i) Open Access

\begin{abstract}
The self-concept refers to a multidimensional construct that organizes a person's self-perceptions into a hierarchical structure comprising global and specific facets. Children's self-concept, however, is believed to be less differentiated and less realistic, as children tend to systematically overestimate their abilities. Since little research has been conducted with children before the beginning of formal schooling, the present longitudinal study aimed to explore the structure of kindergarten children's self-concept, its development during the transition to school, as well as the links between self-concept and achievement in first grade. Counteracting the positively biased self-ratings in children, self-concept was assessed by an innovative measurement instrument that allows for fine-tuned self-evaluations. Structural Equation Modeling showed that kindergarten children's self-concept is already organized in a multidimensional structure, and thus, differentiates much earlier than previously believed. Like the self-concept of adults, kindergarten children's self-concept is composed of domain-specific facets, comprising literacy, mathematical, peer-related and teacher-related self-concept aspects. Moreover, gender stereotype conforming differences-like boys having a higher mathematical and girls having a higher social self-concept-already seem to develop at such a young age. Upon first grade entry, children's academic self-concept increases and becomes positively related to achievement, indicating at least some realism in children's self-perceptions. Taken together, the findings provide new insights into the structure, development, and validity of young children's self-concept, contributing substantially to the generalizability of a multidimensionally organized self-concept.
\end{abstract}

\section{Keywords}

Self-Concept, Academic Achievement, Social Skills, Kindergarten to First Grade Transition, Gender Differences 


\section{Introduction}

Self-concept, broadly defined as a person's perception of him- or herself (Marsh \& Shavelson, 1985), is essential in children's lives because it is believed to be one of the most important predictors of academic, social and emotional development (Marsh, Ellis, \& Craven, 2002). It is therefore not surprising that a child's self-concept is also considered crucial for the successful transition from a play-oriented environment in kindergarten to formal learning in elementary school (Neuenschwander, Röthlisberger, \& Roebers, 2011; Polat \& Akşin, 2015; Stipek, Feiler, Daniels, \& Milburn, 1995). Nevertheless, only a few studies have addressed children's self-concept in this context (Arens et al., 2016), since the self-concept and its measurement constitute challenging topics in such young age groups. Therefore, applying a novel measurement instrument that is highly sensitive to small variances in young children's self-concept, the present longitudinal study focused on kindergarten children's self-concept, particularly on its structure, its development during the transition to school, and its links to achievement in first grade.

Psychological perspectives on the self-concept have a long history, and many different conceptions and definitions regarding the construct have been put forward (Hattie, 1992; Marsh, 1990c). In the 1970s, Shavelson, Hubner, \& Stanton (1976) collated the existing theories and proposed a hierarchical model of self-concept. Following on from this, many studies have provided support for the idea of a multidimensional, hierarchical self-concept (Marsh \& Craven, 2006; Marsh, Craven, \& Martin, 2013).

According to Shavelson et al. (1976), an adult's self-concept is a multifaceted category system that organizes one's self-knowledge into distinct but related facets. The self-concept is seen as being hierarchically organized into three different levels of generality or specificity, respectively. The most general facet called global self-concept is positioned in the apex of the model and represents a person's overall self-perception. The global self-concept is further divided into the components of an academic and a non-academic self-concept, whereby the non-academic self-concept consists of a social, physical and emotional self-concept. On this level of specificity, we focused on the academic and the social self-concept. Regarding the non-academic self-concept, we exclusively focused on the social self-concept, since the self-concept per se is assumed to develop in a context of social interactions (Harter, 2015). Finally, on an even more specific level, the academic self-concept is split into a mathematical self-concept as well as a literacy self-concept (and other school domains in the case of older students). Equally, the social self-concept can be divided into a peer-related self-concept and a significant-others-related self-concept. Regarding the significant others in the present study, we focused on the children's teachers, since teachers represent important persons during the transition from kindergarten to first grade (Leflot, Onghena, \& Colpin, 2010). Thus, our model consisted of a mathematical, a literacy, a peer-related and a teacher-related self-concept. 
With the publication of Shavelson's model, empirical support for a multifaceted self-concept began to emerge (Marsh, 1990b) and-although the hierarchical structure appears to be more complex than originally proposed (Marsh, Byrne, \& Shavelson, 1988; Marsh \& Hattie, 1996; Marsh \& Shavelson, 1985)-the notion that the self-concept is multidimensional has received support from studies of adults, adolescents, and older children (Byrne, 1984, 1996; Marsh, 1990b; Marsh \& Shavelson, 1985; Shavelson \& Bolus, 1982). For young children, however, the findings are still sparse and inconsistent (Arens et al., 2016). Partially, this is because the self-concept has often been examined in relation to achievement; an issue that is less relevant for preschool and kindergarten children (Marsh, 1990b). Moreover, for kindergarten children, there are almost no well-established indicators of preacademic achievement. However and above all, the known uniformly overoptimistic self-concept of young children has led to the assumption of an undifferentiated, ontogenetically early self-concept that undergoes a slow process of differentiation over the course of childhood (Shavelson et al., 1976). Consistent with this assumption, the few studies attempting to clarify the internal structure of children's self-concept suggest a gradual differentiation of the specific facets during the early school years (Byrne \& Shavelson, 1996; Ehm, Lindberg, \& Hasselhorn, 2014; Marsh, Craven, \& Debus, 1991, 1998; Marsh et al., 2002; Marsh \& Hocevar, 1985). That is, although specific self-concept facets could be shown to be present in young children (e.g. Marsh et al., 2002), the discriminant validity of the domain-specific facets seems to increase from age 5 to 8 (Marsh et al., 1991, 1998), and the differentiation becomes intensified from age 8 upwards (Byrne \& Shavelson, 1996; Marsh \& Ayotte, 2003). Studies including younger children, however, do not show a differentiation on the domain-specific level. For example, an investigation by Harter and Pike (1984), including children as young as 4 years, showed the early differentiation as being limited to distinctions on a more general level only (i.e., general competence vs. social acceptance, in Harter's terms). Thus, specific facets of self-concept seem to be present in children at the end of kindergarten and beginning of formal schooling, but the findings are sparse, and more research is required.

In addition to its weak differentiation, young children's self-concept has consistently been reported to be unrealistically positive and only weakly related to actual performance. With increasing age, however, children's self-concept is believed to become more closely linked to external indicators of performance (Marsh, Barnes, Cairns, \& Tidman, 1984). Children's self-concept, therefore, appears to become more realistic with increasing age and thus slowly decreases (Marsh, Byrne, \& Yeung, 1999). In fact, substantial links between self-concept and achievement have been reported in participants from about 8 years on (Marsh \& Craven, 2006). These relations are predominantly domain-specific, that is, self-concept in a specific area is primarily linked to achievement in the corresponding domain (Marsh \& O’Mara, 2008; Möller, Pohlmann, Köller, \& Marsh, 2009). As cross-sectional studies show that these links become stronger 
with children's age, longitudinal studies clearly indicate that the nexus of cause and effect regarding the link between self-concept and achievement is bi-directional (Marsh \& Craven, 2006). That is, self-concept affects achievement (selfenhancement model), and conversely, achievement affects self-concept (skilldevelopment model). Moreover, cross-lagged analyses show that prior self-concept predicts subsequent achievement and vice versa, even when controlling for the respective autoregressions (Huang, 2011). The reciprocal effect model is supported by studies of children from the age of 8 years upwards, but the onset of that bi-directional relationship remains unexplored. Moreover, Marsh and Martin (2011) underlined that research with young children provides insufficient evidence to generalise the described pattern of a mutual relation between self-concept and achievement to kindergarten children. This claim is supported by a few studies with younger children, indicating that their achievement affects subsequent self-concept, but not vice versa (Arens et al., 2016; Helmke \& van Aken, 1995), a fact supporting the skill-development model rather than the reciprocal effect model in young children (Marsh, 1990a). Thus, though the timing of the onset of such reciprocal influences remains unknown, it is well documented that children's self-concept becomes more realistic and more strongly related to achievement over time (Guay, Marsh, \& Boivin, 2003; Marsh et al., 1999).

The fact of the emerging differentiation in children's self-concept, as well as the steadily increasing link to achievement, suggest that children learn about their relative strengths and weaknesses as they get older. Different explanations have been offered for this pattern. In one view, once children enter school, they acquire new skills and abilities which in turn affect their self-perception, leading to a more differentiated and more accurate self-concept (Harter, 2015). According to a second view, middle childhood is marked by a notable development in children's cognitive abilities, that is, children develop fine-tuned skills of self-awareness, begin to evaluate and reflect on their cognitive skills and progress, and learn to compare themselves with others (Harter, 2015). Moreover, self-evaluations based on external criteria-with teachers providing feedback about successes and failures, and the class serving as a social reference group for self-evaluations-become more valid (Eccles, 1999). In other words, with the transition to primary school, children enter a setting in which external demands, individual developmental changes, as well as the interplay of these different systems foster the differentiation and the adjustment of their self-concept (Harter, 2015; Wigfield et al., 1997).

Although the development of the self-concept is seen as being similar for girls and boys, notable differences in how girls and boys perceive and evaluate their abilities have been reported (Herbert \& Stipek, 2005; Marsh, 1987). On the level of the global self-concept, the differences tend to be rather small (Kling, Hyde, Showers, \& Buswell, 1999), slightly favouring boys (Marsh, 1989). On the level of the domain-specific facets, however, counterbalancing effects have been noted (Byrne \& Shavelson, 1987). These differences are mainly consistent with gender 
stereotypes, reinforcing the belief that girls are good at literacy and boys are good at mathematics; indicating girls having a higher literacy self-concept than boys, and boys having a higher mathematical self-concept than girls (Marsh, 1989). This stereotypical pattern has been found as early as the first grade (Eccles, Wigfield, Harold, \& Blumenfeld, 1993) and has been shown to persist in the early school years (Wigfield et al., 1997). Moreover, a meta-analysis by Wilgenbusch and Merrell (1999) clearly demonstrated the persistence of these stereotype-consistent differences for the entire period of compulsory education. In studies of kindergarten children's self-concept, however, very little research has evaluated gender differences (Arens et al., 2016). Thus, the question concerning the onset of this gender-specific development in self-perception arises.

Taken together, although many issues related to self-concept in children have been addressed in the last decades, there are still many unanswered questions. Especially for young children, there is a relative paucity of studies. One reason for this may be found in the lack of appropriate measurement instruments capable of reliably assessing the self-concept in young children (Byrne, 1996; Wylie, 1989).

The psychometrically adequate assessment of young children's self-concept requires a systematic consideration of various features. Instruments designed for young children should provide simplified item contents (Marsh et al., 1991) in the form of developmentally appropriate self-descriptions (Harter \& Pike, 1984). These self-descriptions should be formulated in a concrete manner (Byrne, 1996) and tap specific behaviours or abilities of a child (Harter \& Pike, 1984). Questionnaires should solely include positively worded items to reduce the linguistic complexity (Marsh, 1986). Moreover, a simple and straightforward method of response (Byrne, 1996) with a wide range of answer options is recommended, and an individual administration is required when assessing self-concept in young children (Marsh et al., 1991). Finally, the instrument has to be applicable to a non-reading population. Concerning the latter, Harter and Pike (1983, 1984) proposed the use of pictorial formats and developed the Pictorial Scale of Perceived Competence and Social Acceptance for Young Children (PSPCSA; Harter \& Pike, 1983). In the PSPCSA, children are presented with two pictures, one depicting a competent and the other an incompetent child. The child under assessment has to choose first which of the two pictures is more adequate for him or her and then has to state whether the child in the picture is "a lot like him/her" or just "a little like him/her". By this double binary response format, self-concept responses are coded on a 4-point scale. Unfortunately, the PSPCSA assesses only four domain-specific aspects of self-concept (i.e., cognitive competence, physical competence, peer acceptance and maternal acceptance), whereof only the two higher-order factors (i.e., general competence and social acceptance) could be verified empirically (Harter \& Pike, 1984). Another welldeveloped self-concept instrument, the Self-Description Questionnaire for Preschoolers (SDQP), was developed by Marsh et al. (2002). The SDQP is a downward extension of the SDQ-I (Marsh, 1992) and includes six domain-specific 
scales (i.e., verbal, math, physical, appearance, peers and parents). The SDQP does not provide any pictorial materials. Instead, written presentations are given to the child, and the experimenter reads the items aloud to the child. As in the PSPCSA, the responding child has to answer first a question with yes or no and then has to make a statement, whether the answer is valid "always" or "sometimes". Since there is an additional middle category for children who cannot make a precise decision, the SDQP responses are coded on a 5-point scale. In their initial study, Marsh et al. (2002) showed that preschoolers did differentiate between the assessed domain-specific facets, except between the verbal and the mathematical self-concept, two facets of the self-concept that are especially important in the context of early schooling.

To date, the PSPCSA and the SDQP are the two most widely used instruments for assessing young children's self-concept multidimensionally (Byrne, 1996; Davis-Kean \& Sandler, 2001; Marsh et al., 2002). However, although these two instruments are well-elaborated research tools, we consider the response options limited to 4- and 5-point scales, respectively, as a pivotal shortcoming. In fact, we believe that one reason for why domain-specific self-concept facets appear to be little or non-differentiated in previous studies may lie in the limited variance that is captured by these 4 - and 5-point response scales.

Since young children's self-concept is assumed to be uniformly high (Harter, 1998, 2015) and the differentiation between the domain-specific facets may not yet be strongly developed (Marsh, 1989, 1990b), we believe that a self-concept measurement instrument should provide a more fine-tuned response format. Therefore, we opted for the Pictorial Self-Concept of Attainment Scale, PSCAS for short (for more details see the method section), an innovative measurement instrument that is highly sensitive to small variances in children's self-perceptions, since it provides response options on a pictorial 25-point scale; that is, a realistic size of a child's kindergarten or school class (Roebers, Cimeli, Röthlisberger, \& Neuenschwander, 2012). Thus, children are presented with a depicted reference group, making it easier for them to give a distinctive answer (Helmke, 1999; Nicholls, 1978; Stipek \& Daniels, 1988). In order to help children understand the items correctly, the statements are read aloud by the experimenter during the individual test administration. Due to only 12 positively worded items, test completion is rather short and hence allows for the testing of even very young children. By providing a reference group of a realistic size in a child's everyday life, the PSCAS should allow for counteracting the well-known fact of firmly and positively biased self-ratings in young children, inasmuch as children can select differently high responses within a still high self-concept. In other words, the PSCAS provides a simple and straightforward child-appropriate method of self-concept assessment that allows young children to deliver fine-tuned self-evaluations in domains that are well in the scope of kindergarten children's understanding, and that allows capturing a maximum of even small self-concept differences (if they exist) across children. 


\section{The Present Study}

Applying innovative methods of self-concept assessment, as well as modern and complex statistical methods that allow for better analysing the internal structure of young children's self-concept, the present study assessed self-concept in young children before and right after school entry. The study had four main aims: First, we aimed to explore the internal structure of kindergarten children's self-concept. Despite the initial work of Shavelson et al. (1976) claiming the full hierarchical structure of self-concept to develop only in later childhood (and adolescence), we expected this structure to be discoverable earlier. Using a measurement instrument maximally sensitive to small variances in children's self-perception, we expected to clarify the structure of their self-concept. Second, we sought to assess individual change in self-concept over time at the group level by capturing the critical transition from kindergarten to formal schooling; a phase when children move from a ludic to an early form of achievementoriented daily setting within a short time. Even though children are not formally graded by teachers in the first school year, they constantly get feedback in the form of verbal acknowledgements and symbolic marks. Hence, and given previous research, we expected children's self-concept to decrease as they enter school. Third, we intended to explore self-concept differences between boys and girls. Against the background of consistent gender differences in older children, we expected to find primal stereotype conforming patterns as early as kindergarten. Fourth, we aimed to analyse whether relationships between self-concept and achievement become stronger over time. Therefore, we linked previous $\left(t_{1}\right)$ as well as concurrent $\left(t_{2}\right)$ measures of self-concept to measures of achievement at $t_{2}$. As self-concept is thought to become more realistic with children's age and schooling, we assumed the relations between self-concept and achievement to become stronger as children enter school.

\section{Method}

\subsection{Procedure}

We evaluated children's academic (mathematical and literacy) and social (peer-related and teacher-related) self-concept, as well as their achievement in the corresponding areas. Self-concept was assessed in two waves with a delay of one year, achievement was assessed at the second measurement wave. At the first testing session $\left(t_{1}\right)$, all children attended kindergarten. One year later, shortly after school entry $\left(t_{2}\right)$, children were tested again with the same self-concept instrument as well as with tests of achievement. For academic achievement, children completed standardized paper-pencil tests of mathematical and literacy achievement. For social achievement, children's class teachers completed two questionnaires about each child's social skills. While self-concept was assessed individually, the testing of academic achievement was done in small groups of 5 to 10 children. All data were collected by trained experimenters in isolated rooms in children's kindergartens $\left(\mathrm{t}_{1}\right)$ and schools $\left(\mathrm{t}_{2}\right)$. 


\subsection{Participants}

One hundred and sixty-one children in the German-speaking part of Switzerland participated in the study. Kindergartens were enquired randomly for participation. Only classes with given informed consent by the headmaster as well as the class teacher were tested. Due to missing values in self-concept data, six cases were excluded from the analyses. The final sample consisted of $N=155$ (71 girls, 84 boys). At $t_{1}$, all participants attended kindergarten with a mean age of 6 years and 6 months ( $S D=4.2$ months). At $\mathrm{t}_{2}$, participants attended first grade with a mean age of 7 years and 6 months ( $S D=4.2$ months). Parents gave written informed consent for their children to participate in the study.

\subsection{Materials}

\subsubsection{Self-Concept}

Self-concept was evaluated by the PSCAS (Pictorial Self-Concept of Attainment Scale). The questionnaire is based on the child-appropriate principle of selfconcept assessment developed by Nicholls (1978) (see also Helmke, 1999; Stipek \& Daniels, 1988) and adapted by Cimeli and colleagues (Cimeli, Neuenschwander, Röthlisberger, \& Roebers, 2013; Cimeli, Röthlisberger, Neuenschwander, \& Roebers, 2013). The PSCAS' one-year test-retest reliability is .82 (Roebers et al., 2012), and the correlations between the PSCAS and the corresponding scales of the PSPCSA by (Harter and Pike 1984; German version by Asendorpf \& van Aken, 1993) are between .61 and $.64(p<.01)$, indicating concurrent validity of the PSCAS (Cimeli et al., 2013). The PSCAS measures academic (mathematical and literacy) as well as social (peer-related and teacher-related) aspects of selfconcept with three items for each self-concept facet. The items and their factor loadings are shown in Table 1. Every item is designed as a vertical row of 25 unisex stickmen. Children were told that the top stickman represented the best classmate, whereas the lowest represented the poorest classmate in a given ability. For every item, children were asked to mark the stickman that was most representative of their relative position with respect to their classmates. Each child filled out the questionnaire row by row. For every item, the experimenter repeated the following instruction: "Imagine these stickmen are your classmates. This one (pointing to the top one) is the best one in your class at (e.g.) reading. This one (pointing to the bottom one) is the worst one in your class at reading. And this one (pointing to the middle) is the one in the middle of your class. Which one are you?" Children's self-ratings, ranging from 1 (minimum) to 25 (maximum), were used as the dependent variables, with higher values indicating a more positive self-concept.

\subsubsection{Academic Achievement}

As an external validation of the academic self-concept, children's abilities in the domains of mathematics and literacy were assessed with standardised, curriculum-valid tests. 
Table 1. Factor loadings of the self-concept items on the latent constructs.

\begin{tabular}{cccc}
\hline Latent factor & Item & \multicolumn{2}{c}{ Factor loadings } \\
\hline Mathematics & Calculation skills & .68 & Full model \\
& Counting backwards & .69 & .65 \\
Knowing coins & .69 & .69 \\
Knowing letters & .49 & 69 \\
Literacy & Reading words & .67 & .54 \\
Writing words & .83 & .67 \\
Peer-related & Peers desire to sit next & .69 & .82 \\
To like peers & .64 & .69 \\
To be liked by peers & .75 & .64 \\
Teacher-related & To be liked by the teacher & .76 & .76 \\
& To like the teacher & .67 & .68 \\
\hline
\end{tabular}

Note CFA = Confirmatory Factor Analysis; Full model = Full hierarchical model. In the full model, the latent factors represent the first-order factors. Higher-order factor loadings are shown in Figure 2. All factor loadings are significant at $p<0.001$. All factor loadings are standardised and based on MLE.

Mathematical achievement. Achievement in mathematics was assessed with three subtests of the "Heidelberger Rechentest" (HRT; Haffner, Baro, Parzer, \& Resch, 2005), which measures basic mathematical skills in children. Reported test-retest reliability ranges from .87 to .93 . For the first subtest, magnitude comparison, children had to identify the relation (bigger, smaller or equal) between two magnitudes. For the second subtest, continuation of numerical sequences, children had to detect the correct rules of sequences. The third subtest consisted of addition and subtraction questions. Children were instructed to solve as many problems in sequence as possible until the experimenter stopped the subtest after a given time. The given times were 2 minutes for magnitude comparison, 3 minutes for numerical sequences, and 2 minutes and 30 seconds for the addition and subtraction test. The individual values were composed out of the total of correct answers. The dependent variable was represented by $\mathrm{z}$-standardised values of all three subtests $(\alpha=.81)$ averaged to a single score, with higher values indicating better performance.

Literacy achievement. Attainment in literacy was assessed using tests measuring basic reading and writing skills in early elementary school. Speed of reading was assessed by the "Würzburger Leise Lese Probe" (WLLP; Küspert \& Schneider, 1998) in which children were asked to read a word and identify the matching picture as fast as possible. Reading comprehension was tested with the "Salzburger Lese Screening" (SLS; Mayringer \& Wimmer, 2003) in which children had to judge sentences with regard to their meaningfulness. Spelling was as- 
sessed by the "Hamburger Schreib-Probe" (HSP; May, 1996) in which children had to write down 22 words and one sentence. Reported parallel-form reliabilities are $.82-.93$ for the WLLP, $.90-.92$ for the SLS, and $.93-.98$ for the HSP. In the WLLP and the SLS, children were instructed to solve as many problems in sequence as possible until the experimenter stopped the time. The given times were 5 minutes for the WLLP and 3 minutes for the SLS. For the HSP, children were instructed to work as correctly as possible, without giving a limit in time. The individual values were composed out of the total of correctly solved items. The tests' intercorrelations (WLLP/HSP $r=.58$; WLLP/SLS $r=.83$; HSP/SLS $r=.57)$ were all significant $(p<.001)$. The dependent variable consisted of $\mathrm{z}$-standardised values of all three tests averaged to a single score, with higher values indicating better performance.

\subsubsection{Social Skills}

As an external validation of the social self-concept, class teachers completed two questionnaires about the social behaviour and the social relationships of every child in their class. The response rate was $94.8 \%$. The teachers' responses to all items were given on a five-point Likert-scale, with higher values indicating superior social skills.

Peer-related social skills. To assess children's relationships with their peers, the following five items of the Self- and Other-Oriented Social Competences (SOCOMP; Perren, 2007) questionnaire were used: having many friends, having at least one close friend, ability to maintain a friendship over time, popularity among other children, and being liked by other children. Due to excellent scale reliability ( $\alpha=.88$ ), an average score was computed for each child, with higher values indicating better social skills with peers.

Teacher-related social skills. To assess children's relationship with teachers, the following five items of the Student-Teacher Relationship Scale (STRS; Pianta, 2001) were used: having a good relation to this child, the child seeks comfort if upset, the child shares private information, the child shares emotions, and the child values our relationship. The items resulted in a scale with good reliability $(\alpha=.83)$. For the analyses, an average score for each child was computed, with higher values indicating a more positive and trustful relation to the teacher.

\section{Results}

\subsection{Overview}

Beginning with the analyses of the structure of children's self-concept, factor analytic evidence for the measurement instrument as well as for the expected four-factor structure in children's self-concept is reported first, followed by descriptive statistics and the results of four higher-order models of different hierarchical complexity. Next, the question about stability and change in self-concept during the transition to school is addressed by comparing children's self-concept in kindergarten $\left(t_{1}\right)$ and first grade $\left(t_{2}\right)$. Thereafter, differences in self-concept development between girls and boys are reported. Finally, the concurrent and 
longitudinal relationships between self-concept and academic achievement are assessed such as to get insight if there is already some realism in young children's self-concept.

\subsection{Analysis Plan}

In statistical terms, the self-concept structure proposed by Shavelson et al. (1976) is called a hierarchical or higher-order model, with first-, second-, and thirdorder factors (Garson, 2015; Kline, 2015). The first-order factors represent the four domain-specific facets (mathematical, literacy, peer-related and teacher-related self-concept), the second-order factors the two domain-general facets (academic and social self-concept), and the third-order factor the global self-concept. To evaluate the suitability of this model as a description of young children's self-concept, Structural Equation Modeling (SEM) was applied using Amos software (Arbuckle, 2013). Taking into account the left-skewed distribution of the self-concept data, $\left(S D_{\text {skewness }}=.19\right.$; skewness numerical $=-.78$ at $\mathrm{t}_{1}$ and -.71 at $\mathrm{t}_{2}$; skewness literacy $=-.44$ at $\mathrm{t}_{1}$ and -.69 at $\mathrm{t}_{2}$; skewness peer-related $=-.89$ at $\mathrm{t}_{1}$ and -.80 at $\mathrm{t}_{2}$; skewness teacher-related $=-1.33$ at $\mathrm{t}_{1}$ and -1.46 at $t_{2}$ ) all models reported below were also computed with various distribution free estimates and compared to the solutions provided by Maximum-Likelihood (ML) estimation (Finney \& DiStefano, 2013; Kline, 2011). Since the deviations from the results obtained by ML were negligible and ML is claimed to provide empirically more accurate estimates (Olsson, Foss, Troye, \& Howell, 2000), ML results are reported. Similarly, considering the data's skew in further analyses, all correlations were computed according to Spearman rank order correlations $\left(r_{s}\right)$, change over time was examined by Wilcoxon-Tests, and cross-sectional gender differences were analysed by Mann-Whitney-U-Tests.

\subsection{Confirmatory Factor Analysis}

As a first step, a Confirmatory Factor Analysis (CFA) was conducted to assess if the four assumed domain-specific factors (mathematical, literacy, peer-related and teacher-related) already existed in kindergarten children's self-concept, as well as to verify if all items substantially loaded on the expected factors. Therefore, a restrictive factor structure was tested where each indicator variable was allowed to load only on the respective theoretically specified factor and no residuals were allowed to correlate. This CFA provided a good model fit with a non-significant $\mathrm{Chi}^{2}\left(\chi^{2}=52.12, d f=48, p=.317\right)$, a Goodness of Fit Index (GFI) of .950, and a Root Mean Square Error of Approximation (RMSEA) of .024. All factor loadings (see Table 1 ) were statistically significant at $p<.001$. Thus, the CFA supported the expected four-factor structure in kindergarten children's self-concept.

To ensure that the same factor structure persisted in first grade, a similar CFA was conducted for $t_{2}$ data. The results again confirmed the four-factor structure with an acceptable model fit $\left(\chi^{2}=104.02, d f=48, p=.000\right.$; GFI $=.899$; RMSEA $=.087$ ) and statistical significant factor loadings at $p<.001$. Hence, the basic 
structure of self-concept found in kindergarteners remained the same when the children attended school, indicating children's self-concept to be substantively equal throughout the testing sessions.

\subsection{Descriptive Statistics}

As CFA confirmed the four-factor structure, composite scores were computed for all four domain-specific factors by averaging each factor's three items. The resulting composite scores ranged from 1 (minimum) to 25 (maximum). The scale reliabilities $\left(t_{1}\right)$ were adequate with $\alpha=.73$ for mathematical, $\alpha=.69$ for literacy, $\alpha=.74$ for peer-related, and $\alpha=.77$ for teacher-related self-concept. The means and standard deviations of the self-concept's composite scores are shown in Table 2.

In agreement with our assumption, self-concept was clearly above scale average (i.e., 13) in all four facets on both measurement occasions, a finding underlining the over-optimism in self-concept ascribed to early childhood, and that holds true for girls and boys (see Table 2). The Mann-Whitney-U-Tests unveiled only small gender differences. Girls had a significantly higher social self-concept (peer-related $p=.037$, teacher-related $p=.023$ ) compared to boys, but only at $\mathrm{t}_{1}$, whereas boys had a higher mathematical self-concept $(p=.045)$ compared to girls, but only at $t_{2}$. Since the differences in boys' and girls' self-concept were small and limited to specific time-points, the self-concept structure was analysed across gender for the following models.

\subsection{Structure of Kindergarten Children's Self-Concept}

By performing the CFA, not only could the expected four-factor structure be validated, but also the existence of higher-order factors could be explored. In other words, CFA allowed to compare the correlations between the four first-order factors, and thus, to consider if discriminant and convergent validity indicated the expected second-order factors, namely an academic second-order factor

Table 2. Descriptive statistics of self-concept in first and second measurement-point.

\begin{tabular}{|c|c|c|c|c|c|c|c|c|c|c|c|c|}
\hline & \multicolumn{6}{|c|}{ First measurement-point (kindergarten) } & \multicolumn{6}{|c|}{ Second measurement-point (first grade) } \\
\hline & \multicolumn{2}{|c|}{ Total } & \multicolumn{2}{|c|}{ Girls } & \multicolumn{2}{|c|}{ Boys } & \multicolumn{2}{|c|}{ Total } & \multicolumn{2}{|c|}{ Girls } & \multicolumn{2}{|c|}{ Boys } \\
\hline & $M$ & $(S D)$ & $M$ & $(S D)$ & $M$ & $(S D)$ & $M$ & $(S D)$ & $M$ & $(S D)$ & $M$ & $(S D)$ \\
\hline \multicolumn{13}{|c|}{ Academic self-concept } \\
\hline Mathematical & 18.34 & $(6.25)$ & 18.50 & $(6.94)$ & 18.19 & $(5.65)$ & 19.25 & $(4.74)$ & 18.34 & $(5.05)$ & 20.12 & $(4.35)$ \\
\hline Literacy & 16.33 & $(6.60)$ & 17.12 & $(6.47)$ & 15.66 & $(6.67)$ & 20.01 & $(4.34)$ & 20.25 & $(4.17)$ & 19.81 & $(4.50)$ \\
\hline \multicolumn{13}{|l|}{ Social self-concept } \\
\hline Peer-related & 20.31 & $(4.90)$ & 20.87 & $(5.21)$ & 19.84 & $(4.61)$ & 19.51 & $(4.75)$ & 19.03 & $(5.14)$ & 19.90 & (4.38) \\
\hline Teacher-related & 20.68 & $(5.15)$ & 21.66 & $(4.79)$ & 19.85 & $(5.33)$ & 20.60 & $(4.38)$ & 21.02 & $(4.23)$ & 20.25 & $(4.50)$ \\
\hline
\end{tabular}

Note: Means $(M)$ and standard deviations $(S D)$ of self-concept are shown for total sample $(n=155)$, girls $(n=71)$ and boys $(n=84)$. Mean age of total sample was 6 years and 6 months at $\mathrm{t}_{1}$ and 7 years and 6 months at $\mathrm{t}_{2}$. Range of self-concept was $1-25$. 
including mathematical and literacy self-concept, and a social second-order factor including peer-related and teacher-related self-concept.

As shown in Figure 1, the factors' intercorrelations were in agreement with our assumption. The highest factor intercorrelations were found for mathematical and literacy $(r=.75, p<.001)$ and for peer-related and teacher-related self-concept $(r=.67, p<.001)$, respectively. All other intercorrelations were, though statistically significant, considerably lower, indicating the link between mathematical and literacy self-concept as well as the one between peer- and teacher-related self-concept to be the most pertinent ones. Nevertheless, since all factors were significantly intercorrelated, the existence of a general factor was indicated too.

Since higher-order factors could be expected in the form of second-order and third-order factors, the original model proposed by Shavelson et al. (1976) was tested first with self-concept data assessed at $t_{1}$ by applying SEM. To estimate the full model (see Figure 2), the mathematical, literacy, peer-related and teacher-related self-concept were entered as first-order factors, the academic and the social self-concept as second-order factors, and the global self-concept as a third-order factor. Again, each indicator variable was allowed to load only on the factor that it was specified to measure and no residuals were allowed to correlate. Considering the factor loadings and the global model fit, this full hierarchical model represented children's self-concept very well, with significant loadings $(p<.001)$ between .54 and .93 (see also Table 1 and Figure 2), a non-significant $\mathrm{Chi}^{2}\left(\chi^{2}=55.67, d f=51, p=.303\right.$ ), a GFI of .956 , and an RMSEA of .024 (see also Table 3).

However, according to theoretical assumptions (Shavelson et al., 1976), the hierarchical structure of self-concept should only emerge over the course of elementary school years, whereas younger children's self-concept is described as being general and undifferentiated. In addressing this issue, various models of lower complexity were computed. In the most general and parsimonious model (Model 1), all 12 items were direct indicators of one single global factor. The factor loadings were all moderate (.51 to .62), and the overall model fit was rather poor (see Table 3). In the following models, second-order factors were included in addition to the global factor. For Model 2, these were the domain-general factors, namely the academic and the social self-concept, with the

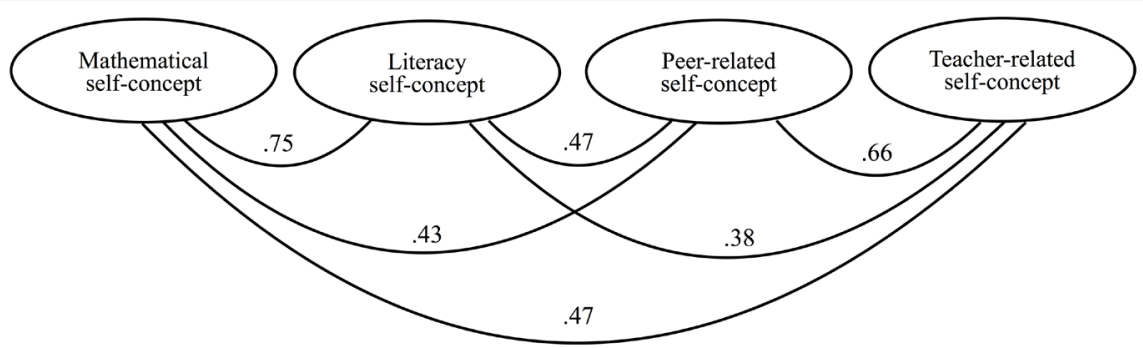

Figure 1. Confirmatory Factor Analysis: The nonhierarchical model of self-concept. Factor correlations (by MLE) are shown for kindergarten children. 


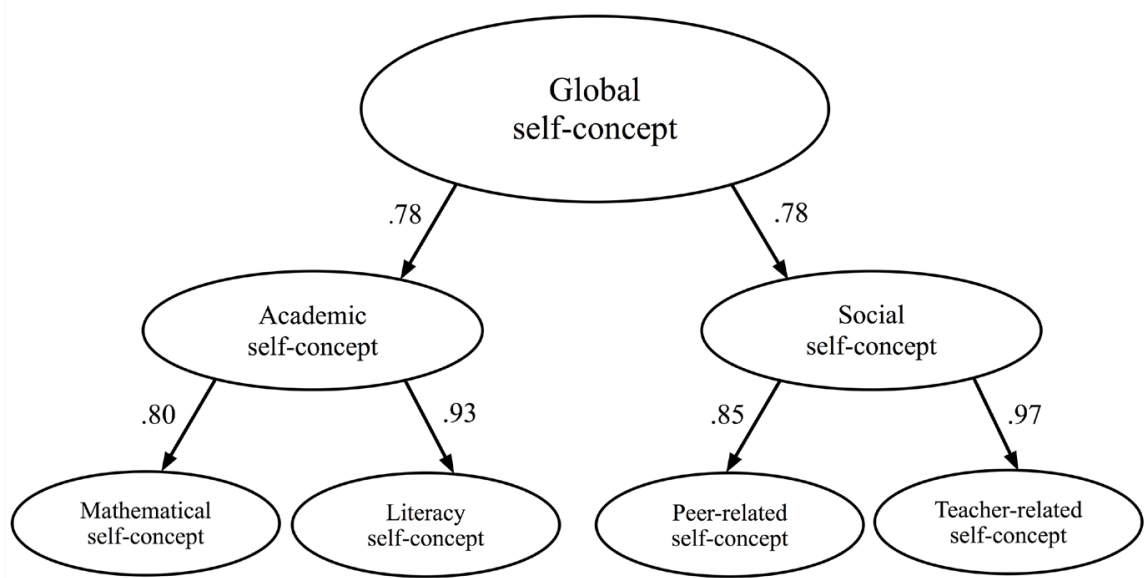

Figure 2. Full hierarchical model of self-concept. Factor loadings (by MLE) are shown for kindergarten children.

Table 3. Goodness of fit indices of different models.

\begin{tabular}{ccccccccc}
\hline Model & $\chi^{2}$ & $p$ & $d f$ & $\chi^{2 / d f}$ & GFI & RMSEA & AIC & BIC \\
\hline Model 1 (global factor only) & 211.55 & .000 & 54 & 3.92 & .773 & .138 & 295.56 & 332.59 \\
$\begin{array}{c}\text { Model 2 } \\
\text { Model 3 }\end{array}$ & 107.17 & .000 & 53 & 2.02 & .887 & .081 & 157.12 & 233.20 \\
$\begin{array}{c}\text { (global + domain-general factors) } \\
\text { Model }\end{array}$ & 73.62 & .017 & 50 & 1.47 & .928 & .055 & 129.62 & 214.83 \\
$\begin{array}{c}\text { (global + domain-specific factors) } \\
\begin{array}{c}\text { Full hierarchical model } \\
\text { (global + domain-general + } \\
\text { domain-specific factors) }\end{array}\end{array}$ & 55.67 & .303 & 51 & 1.09 & .956 & .024 & 109.67 & 191.84 \\
\hline
\end{tabular}

Note: $\chi^{2}=$ Chi-square, $d f=$ degrees of freedom, $\chi^{2 / d f}=$ Chi-square statistics, GFI $=$ Goodness of Fit Index, RMSEA $=$ Root Mean Square of Approximation, AIC $=$ Akaike information criterion, BIC $=$ Bayesian in formation criterion. All fit indices are reported for the first measurement-point (kindergarten).

six matching items loading on the corresponding factor. For Model 3, in contrast, these were the domain-specific factors, namely the mathematical, the literacy, the peer-related and the teacher-related self-concept, with the three matching items loading on each factor. The first-order factor loadings in Model 2 and Model 3 were similar, ranging from .49 to .80 in Model 2 and from .49 to .83 in Model 3, respectively. As shown in Table 3, both models resulted in a significant $\mathrm{Chi}^{2}$-test, indicating that the models did not fit the data well. Also, the GFI and the RMSEA were poor, being slightly superior for Model 3, favouring the structure with one global and four domain-specific factors over the model with one global and two broader factors. Nevertheless, the combination of the four domain-specific, the two domain-general, and the overall global factor assembled to the initial full hierarchical model represented kindergarten children's self-concept by far the best.

All models were also computed with self-concept data of $t_{2}$. Similar to kindergarten children's self-concept, first graders' self-concept was best represented by the full hierarchical structure. Although the fit of the first grade model was lower as compared to the kindergarten model $\left(\chi^{2}=106.348, d f=51, p=.000\right.$, GFI 
$=.897$, RMSEA $=.084)$, the model still represented children's self-concept well.

\subsection{Stability and Change}

We were also interested in the intra-individual stability of self-concept during the transition period from kindergarten to formal schooling. The findings provided by SEM indicated that children's self-concept is stable in its structure, at least at the group level. However, the level of children's self-concept might change over time; absolutely, in terms of the magnitude, and relatively, regarding the individual rank within one's reference group. As shown in Table 4, Spearman correlations between $t_{1}$ and $t_{2}$ were, though significant, rather low, indicating substantial individual variability in young children's self-concept over time.

As to the participants' self-concept level in different domains and the potential changes over time at the group level, the Wilcoxon-Test showed significant increases in mathematical $(p=.033)$ and literacy $(p<.001)$ self-concept over time (see Table 4). In contrast, the trend for the social areas was, though insignificant, negative. Thus, as academic self-concept increased over time, social self-concept remained at about the same level.

However, when looking at boys' and girls' self-concept changes over time separately, a different picture emerged. While Wilcoxon-Tests showed girls' peer-related self-concept to have decreased significantly $(p=.022)$, the boys' one remained at the same level with a tendency of a slight increase (see Table 4). Furthermore, boys' mathematical self-concept increased significantly $(p=.007)$, whereas girls' mathematical self-concept remained at the same level, or slightly tended to decrease. Overall, analyses revealed various indications that girls' and boys' self-concept followed different developmental trajectories.

\subsection{Linking Early Self-Concept to Achievement}

To examine self-concept accuracy in terms of an emerging realism of young children's self-concept, domain-specific relations between self-concept and

Table 4. Stability and chance of self-concept.

\begin{tabular}{|c|c|c|c|c|c|c|c|c|c|}
\hline & \multicolumn{3}{|c|}{ Total } & \multicolumn{3}{|c|}{ Girls } & \multicolumn{3}{|c|}{ Boys } \\
\hline & Change & $r_{s}$ & $\eta^{2}$ & Change & $r_{s}$ & $\eta^{2}$ & Change & $r_{s}$ & $\eta^{2}$ \\
\hline \multicolumn{10}{|l|}{ Academic self-concept } \\
\hline Mathematical & $+.91^{*}$ & $.248^{* *}$ & .19 & -.17 & .217 & .00 & $+1.82^{* *}$ & $.289^{* *}$ & .08 \\
\hline Literacy & $+3.68^{* *}$ & $.285^{* *}$ & .24 & $+3.13^{* *}$ & .187 & .18 & $+4.15^{* *}$ & $.356^{* *}$ & .29 \\
\hline \multicolumn{10}{|l|}{ Social self-concept } \\
\hline Peer-related & -.81 & $.163^{*}$ & .02 & $-1.84^{* *}$ & .095 & .07 & +.63 & $.264^{*}$ & .00 \\
\hline Teacher-related & -.69 & $.376^{* *}$ & .00 & -.63 & $.278^{*}$ & .02 & +.41 & $.425^{* *}$ & .01 \\
\hline
\end{tabular}

Note: Change from first measurement-point (kindergarten) to second measurement-point (first grade) in absolute values on the PSCAS (1 minimum, 25 maximum). Significances of change in absolute values are based on Wilcoxon-Tests. Significances of Spearman correlations $\left(r_{s}\right)$ are two-tailed. Effect sizes $\eta^{2}$ are based on GLM with repeated measures. ${ }^{*} p<.05 ;{ }^{* *} p<.01$. 
achievement were analysed based on Spearman correlations. According to developmental theories, young children's self-concept is not consistently linked to actual performance (Eccles, 1999; Harter, 2015). Nevertheless, self-concept has often been reported to be an important predictor of later achievement. Thus, we related self-concept at $t_{1}$ and self-concept at $t_{2}$ to the achievement measures at $t_{2}$. As can be seen in Table 5(a), correlations between self-concept at $t_{1}$ and achievement at $t_{2}$ were low and non-significant. Only peer-related self-concept was significantly related to mathematical achievement, however, negatively. Thus, self-concept in kindergarten did not reliably predict school achievement in first grade.

However, the correlations between concurrent measures, that is, $\mathrm{t}_{2}$-self-concept and $t_{2}$-achievement, were statistically significant at $p<.001$ in all matching aspects (see Table 5(b)). More precisely, mathematical achievement and mathematical self-concept, as well as literacy achievement and literacy self-concept, were significantly correlated, indicating that self-concept domains and their domain-specific achievements were differentially related. This was also shown for the social context. Namely, peer-related social skills were significantly correlated with peer-related self-concept, and teacher-related social skills were significantly related to teacher-related self-concept, indicating some realism in children's academic and social self-concept.

Furthermore, correlations within the academic area were also significant for the adjacent factor, meaning that mathematical achievement was also related to literacy self-concept, and literacy achievement was also related to mathematical self-concept (see Table 5(b)). However, these correlations were, though significant at $p<.05$, lower than the correlations between the matching aspects, pointing to a weak differentiation in young children's academic self-concept. Finally, the non-significant correlations between the unrelated factors (i.e., academic and social facets) are noteworthy too, underpinning the discriminant validity of the construct of self-concept in early years, and thus pleading for children's self-perception to be differentiated on a domain-specific level, extending the scope of established theory and previous research.

\section{Discussion}

In the present study, we assessed kindergarten children's self-concept with an age-appropriate and variance-sensitive instrument that allowed to capture subtle differences in children's self-perceptions. Confirming our assumption, we found that young children's self-concept is more differentiated than previously assumed, with kindergarten children's self-concept being organised as a multidimensional hierarchical structure that comprises at least four domain-specific facets (mathematical, literacy, peer-related and teacher-related self-concept). During children's transition to school, these domain-specific facets underwent different developmental trajectories. While social self-concept was stable, academic self-concept-contrary to expectations-increased significantly over time. 
Table 5. (a) Predictive validity of self-concept; (b) Concurrent validity of self-concept.

(a)

\begin{tabular}{ccccc}
\hline & \multicolumn{2}{c}{ Academic achievement } & \multicolumn{2}{c}{ Social skills } \\
\cline { 2 - 5 } & Mathematics & Literacy & Peer-related & Teacher-related \\
\hline Academic self-concept & & & & \\
\hline Mathematical & .054 & -.010 & -.002 & .020 \\
Literacy & .095 & .131 & .158 & .108 \\
\hline Social self-concept & & & & .007 \\
\hline Peer-related & $-.170 *$ & -.040 & -.017 & .060 \\
Teacher-related & .102 & -.146 & .016 &
\end{tabular}

Note: Spearman correlations between self-concept in first measurement-point (kindergarten) and achievement in second measurement-point (first grade). ${ }^{*} p<.05 ;{ }^{* *} p<.01$.

(b)

\begin{tabular}{ccccc}
\hline & \multicolumn{2}{c}{ Academic achievement } & \multicolumn{2}{c}{ Social skills } \\
\cline { 2 - 5 } & Mathematics & Literacy & Peer-related & Teacher-related \\
\hline Academic self-concept & & & & \\
\hline Mathematical & $.290^{* *}$ & $.181^{*}$ & .175 & .057 \\
Literacy & $.198^{*}$ & $.361^{* *}$ & .086 & -.021 \\
\hline Social self-concept & & & & .174 \\
\hline Peer-related & .000 & .009 & $.267^{* *}$ & $.253^{* *}$ \\
\hline Teacher-related & .000 & -.001 & .128 & \\
\hline
\end{tabular}

Note: Spearman correlations between self-concept in second measurement-point (first grade) and achievement in second measurement-point (first grade). ${ }^{*} p<.05 ;{ }^{* *} p<.01$.

The separate consideration of boys and girls, however, indicated that especially boys' self-concept increased during the transition to school, whereas girls' self-concept decreased in all facets, except for literacy. Finally, we found that children's self-concept is related to objective measures of attainment in first grade. Thus, our findings offer new insights into the structural organisation of young children's self-concept, its development during school enrolment, as well as into its validity.

Regarding the first aim of our study, namely to explore the internal structure of young children's self-concept with a sensitive, age-adequate measurement instrument, our finding of a differentiated self-concept in kindergarten children contrasts with the common claim that the differentiation into specific facets only arises during the early school years. With a few exceptions (e.g. Marsh et al., 1991, 1998), the majority of previous work showed the self-concept structure in children before the beginning of formal schooling to be limited to a more general level, consisting only of an academic and a non-academic self-concept (Harter \& Pike, 1984; Marsh et al., 2002). Supporting these few exceptional findings, we found clear evidence for a differentiation on the domain-specific level in kin- 
dergarten children's self-concept. On the one hand, this was supported by the good model fit of the CFA, indicating the four specified factors to be related but clearly distinguishable even in kindergarten children. On the other hand, the differentiated organisation was underlined by a very good model fit of the full hierarchical model in terms of Shavelson et al. (1976). Completing the original Shavelson model, future research should include additional measures of physical and emotional self-concept. Since our results lend support to kindergarten children's self-perceptions being differentiated in the area of academic and social self-concept, early differentiations in the domains of physical and emotional self-concept are also to be expected.

We believe that the differences between our findings and those of earlier studies reflect differences in the measurement instruments applied. The PSCAS, as set out by the present study, has been designed to be sensitive to small differences in children's individual self-concepts. Although pictorial test formats have been used for a long time in assessing self-concept in young children (Harter \& Pike, 1984) and now find application in adults testing too (Harris, Donnellan, \& Trzesniewski, 2017), they are all lacking a broad range of response options and an adequate frame of reference for young children. What is new with the PSCAS, hence, is the items' graphical illustration of the whole class that provides response options on a 25-point scale; that is, a realistic size of a child's class. Empirical research shows that children within regular classroom settings can precisely rank the ability of their classmates (Harter, 1993). The PSCAS takes advantage of these rank ordering skills and thereby counteracts the fact of firmly and positively biased self-ratings in young children, since the pictorial illustration of the class provides a simple and straightforward method of response that allows young children to deliver fine-tuned self-evaluations. Capturing such nuanced self-ratings, the PSCAS allowed the detection of an early differentiation in young children's self-concept.

The early differentiation into domain-specific self-concept facets uncovered by the present study is remarkable, especially when considering the fact that kindergarten children, as being the case for the most part of Switzerland, neither had specific instructions or training nor systematic feedback in the domains of literacy and mathematics yet. Nonetheless, they seem to be able to differentiate between these specific factors, since they clearly distinguish their ability in literacy from their ability in mathematics. Equally, kindergarten children differentiate between various forms of social skills, since they distinguish peer-related social skills from social skills when interacting with their teacher. Since the present study's results suggest that domain-specific self-evaluations emerge already before children attend school, future research should explore the reasons for this early differentiation, especially in the area of academic self-concept. Possible sources for the early differentiation may lie in-rather unsystematic-feedback from parents, kindergarten teachers, siblings, and peers, or in factors like perceived interest and joy in specific playful tasks, together with invested time and effort. 
Our study's second purpose was to consider developmental changes over time as children move from a play-oriented setting in kindergarten to formal learning in first grade. Within the domain-specific facets, distinct developmental trends were observed. While the academic facets of self-concept (both literacy and mathematics) increased over the period of transition from kindergarten to first grade, the social facets of self-concept (both peer-related and teacher-related) remained at about the same level.

At first glance, the finding of an increasing academic self-concept seems to contradict the assumption of a general decrease in self-concept during the elementary school years (Robins \& Trzesniewski, 2005). According to Harter (2015), young children's self-concept is overoptimistically high, but decreases as soon as children enter school and their self-perceptions become more realistic. However, taking into account the fact of increasing academic competencies in this transition phase, our result can be interpreted in a way that is compatible with Harter's (2015) view. Upon school entrance, children acquire new academic skills, and consequently, presuming at least some realism in children's self-perception, their self-concept should increase. Similarly, the finding of a constant level in social self-concept is consistent with this argument. Our interpretation of relatively unchanged levels of social self-concept is that kindergarten is thought to provide prerequisites for social life via the need to follow social rules and social standards. As kindergarten children spend most of their time playing with peers and engaging with their kindergarten teacher, social skills already get emphasised. Thus, school enrolment may not provide much additional support for the development of social skills. Another possible explanation for why children's academic self-concept did not decrease from $t_{1}$ to $t_{2}$ is that in the present study, the second measurement wave was already at the beginning of first grade, a point in time where self-concept may not yet have started to decrease. Moreover, in the first school year, teachers do not formally grade children, and feedbacks are probably rather kind and favourable, thus rather supporting than discouraging children's self-perceptions. Hence, future research should include further measurement waves in close temporal proximity to detect the developmental trajectories of early self-concept.

Considering the third purpose of this study, namely to explore the gender-specific differences in young children's self-concept, results show that girls have a higher social self-concept than boys in kindergarten. This difference, however, dissipates as children enter school where, in contrast, boys start developing a higher mathematical self-concept compared to girls. Since the correlations between the domain-specific facets of self-concept in kindergarten and first grade were, although statistically significant, rather low, we further examined gender-specific developments in self-concept. Results showed that boys' self-concept increased in all four domain-specific facets, whereas girls' self-concept decreased in all facets, except for literacy. This finding demonstrates how early stereotyped gender differences emerge, and how early girls develop a lower self-concept. As Epstein $(1984,1991)$ emphasised, self-perceptions not only be- 
come resistant to change with increasing age but constantly provoke self-fulfilling prophecies. Hence, a low self-concept would inevitably lead to low performance. Against the background of increasing stability in children's self-perceptions, especially girls would benefit from kindergarten teachers and parents being aware of the early decrease in self-concept and them attempting to prevent the onset of the alleged negative cycle of low self-concept and low performance.

The fourth aim of the study addressed the relation between self-concept and achievement. Examining the cross-sectional links of concurrent self-concept facets and achievement in first graders, our results suggested that the domainspecific facets of self-concept are positively correlated with measures of attainment in all four domains. This finding clearly points to early realism in children's self-perception and indicates that first graders' self-concepts are valid. Furthermore, the above-noted conclusion of an early differentiation in children's self-concept is strengthened by the finding of divergent validity, inasmuch as the correlations between self-concept and attainment were mainly domain-specific, and thus, underlining the distinctiveness of the domain-specific factors of selfconcept.

Following up on the unveiled cross-sectional links between self-concept and achievement in first graders, we expected self-concept assessed in the previous year to predict achievement in first grade. In line with prior research, however, nearly no relation between earlier self-concept and later attainment was found (Huang, 2011; Marsh \& Martin, 2011). As previous studies have documented, influences in the sense of a skill-development model may emerge first (Arens et al., 2016; Helmke \& van Aken, 1995). However, due to a lack of achievement data for kindergarten and as a limiting factor of the present study, it was not possible to address this issue. Thus, it remains unclear whether early academic or pre-academic skills would have predicted later self-concept. Future research should, therefore, extend our study by assessing achievement also in kindergarten.

\section{Conclusion}

In summary, our findings are striking in supporting a high degree of differentiation in self-concept in young kindergarten children. Furthermore, the innovative method of assessing self-concept has been validated by showing associations between aspects of self-concept and very early differences in educational attainment. We believe the current study opens up a wide variety of future research directions to confirm and refine the degree of differentiation in self-concept in preschool children by applying fine-tuned pictorial measurement instruments. Regarding the practical significance of the present study, especially the findings of a differentiation on the domain-specific level, as well as the stereotypical gender differences in children's self-concept, both emerging even before children attend school, unveil the crucial need for finding ways to enhance very young children's self-concept, since there is substantiated belief in the power of such 
support in contributing substantially to improvements in educational attainment and mental health.

\section{References}

Arbuckle, J. (2013). Amos (Version 22.0) [Computer Program]. Chicago: SPSS/IBM.

Arens, A. K., Marsh, H. W., Craven, R. G., Yeung, A. S., Randhawa, E., \& Hasselhorn, M. (2016). Math Self-Concept in Preschool Children: Structure, Achievement Relations, and Generalizability across Gender. Early Childhood Research Quarterly, 36, 391-403. https://doi.org/10.1016/j.ecresq.2015.12.024

Asendorpf, J. B., \& van Aken, M. A. G. (1993). Deutsche Versionen der Selbstkonzeptskalen von Harter. Zeitschrift für Entwicklungspsychologie und Pädagogische Psychologie, 25, 64-86.

Byrne, B. M. (1984). The General/Academic Self-Concept Nomological Network: A Review of Construct Validation Research. Review of Educational Research, 54, 427-456. https://doi.org/10.3102/00346543054003427

Byrne, B. M. (1996). Measuring Self-Concept across the Life Span. Issues and Instrumentation. Washington DC: American Psychological Association. https://doi.org/10.1037/10197-000

Byrne, B. M., \& Shavelson, R. J. (1987). Adolescent Self-Concept: Testing the Assumption of Equivalent Structure across Gender. American Educational Research Journal, 24, 365-385. https://doi.org/10.3102/00028312024003365

Byrne, B. M., \& Shavelson, R. J. (1996). On the Structure of Social Self-Concept for Pre-, Early, and Late Adolescents: A Test of the Shavelson, Hubner, and Stanton (1976) Model. Journal of Personality and Social Psychology, 70, 599-613.

https://doi.org/10.1037/0022-3514.70.3.599

Cimeli, P., Neuenschwander, R., Röthlisberger, M., \& Roebers, C. M. (2013). Das Selbstkonzept von Kindern in der Schuleingangsphase. Zeitschrift für Entwicklungspsychologie und Pädagogische Psychologie, 45, 1-13.

https://doi.org/10.1026/0049-8637/a000075

Cimeli, P., Röthlisberger, M., Neuenschwander, R., \& Roebers, C. M. (2013). Stellt ein niedriges Selbstkonzept einen Risikofaktor für Anpassungsprobleme nach dem Schuleintritt dar? Kindheit und Entwicklung, 22, 105-112.

https://doi.org/10.1026/0942-5403/a000106

Davis-Kean, P. E., \& Sandler, H. M. (2001). A Meta-Analysis of Measures of Self-Esteem for Young Children: A Framework for Future Measures. Child Development, 72, 887-906. https://doi.org/10.1111/1467-8624.00322

Eccles, J. S. (1999). The Development of Children Ages 6 to 14. The Future of Children, 9, 30-44. https://doi.org/10.2307/1602703

Eccles, J. S., Wigfield, A., Harold, R. D., \& Blumenfeld, P. (1993). Age and Gender Differences in Children's Self- and Task Perceptions during Elementary School. Child Development, 64, 830-847. https://doi.org/10.2307/1131221

Ehm, J.-H., Lindberg, S., \& Hasselhorn, M. (2014). Reading, Writing, and Math SelfConcept in Elementary School Children: Influence of Dimensional Comparison Processes. European Journal of Psychology of Education, 29, 277-294. https://doi.org/10.1007/s10212-013-0198-x

Epstein, S. (1984). Entwurf einer Integrativen Persönlichkeitstheorie. In S. Filipp (Ed.), Selbstkonzept-Forschung: Probleme, Befunde, Perspektiven (Vol. 2, pp. 15-45). Stuttgart: Klett-Cotta. 
Epstein, S. (1991). Cognitive-Experiential Self-Theory: An Integrative Theory of Personality. In R. C. Curtis (Ed.), The Relational Self: Theoretical Convergences in Psychoanalysis and Social Psychology (pp. 111-137). New York, NY: The Guilford Press.

Finney, S. J., \& DiStefano, C. (2013). Non-Normal and Categorical Data in Structural Equation Modeling. In G. R. Hancock, \& R. O. Mueller (Eds.), Structural Equation Modeling: A Second Course (2nd ed., pp. 439-492). Charlotte, NC: Information Age Publishing.

Garson, G. D. (2015). Structural Equation Modeling. North Carolina: Statistical Publishing Associates.

Guay, F., Marsh, H. W., \& Boivin, M. (2003). Academic Self-Concept and Academic Achievement: Developmental Perspectives on Their Causal Ordering. Journal of Educational Psychology, 95, 124-136. https://doi.org/10.1037/0022-0663.95.1.124

Haffner, J., Baro, K., Parzer, P., \& Resch, F. (2005). Heidelberger Rechentest (HRT 1-4). Göttingen: Hogrefe.

Harris, M. A., Donnellan, M. B., \& Trzesniewski, K. H. (2017). The Lifespan Self-Esteem Scale: Initial Validation of a New Measure of Global Self-Esteem. Journal of Personality Assessment, 1-12.

Harter, S. (1993). Causes and Consequences of Low Self-Esteem in Children and Adolescents. In R. F. Baumeister (Ed.), Self-Esteem. The Puzzle of Low Self-Regard (pp. 87-116). New York, NY: Premium Press.

Harter, S. (1998). The Development of Self-Representations. In W. Daman, \& S. Eisenberg (Eds.), Handbook of Child Psychology (5th ed., pp. 553-617). New York, NY: Guilford Press.

Harter, S. (2015). The Construction of the Self: Developmental and Sociocultural Foundations. New York, NY: Guilford Publications.

Harter, S., \& Pike, R. (1983). Procedural Manual to Accompany the Pictorial Scale of Perceived Competence and Social Acceptance for Young Children. Denver, CO: University of Denver.

Harter, S., \& Pike, R. (1984). The Pictorial Scale of Perceived Competence and Social Acceptance for Young Children. Child Development, 55, 1969-1982.

https://doi.org/10.2307/1129772

Hattie, J. (1992). Self-Concept. Hillsdale, NJ: Lawrence Erlbaum.

Helmke, A. (1999). From Optimism to Realism? Development of Children's Academic Self-Concept from Kindergarten to Grade 6. In A. S. Weinert Wolfgang (Ed.), Individual Development from 3 to 12: Findings from the Munich Longitudinal Study (pp. 198-221). Cambridge: Cambridge University Press.

Helmke, A., \& van Aken, M. A. (1995). The Causal Ordering of Academic Achievement and Self-Concept of Ability during Elementary School: A Longitudinal Study. Journal of Educational Psychology, 87, 624-637. https://doi.org/10.1037/0022-0663.87.4.624

Herbert, J., \& Stipek, D. (2005). The Emergence of Gender Differences in Children's Perceptions of Their Academic Competence. Journal of Applied Developmental Psychology, 26, 276-295. https://doi.org/10.1016/j.appdev.2005.02.007

Huang, C. (2011). Self-Concept and Academic Achievement: A Meta-Analysis of Longitudinal Relations. Journal of School Psychology, 49, 505-528. https://doi.org/10.1016/j.jsp.2011.07.001

Kline, R. B. (2011). Principles and Practice of Structural Equation Modeling (3rd ed.). New York, NY: The Guilford Press.

Kline, R. B. (2015). Principles and Practice of Structural Equation Modeling (4th ed.). 
New York, NY: Guilford Publications.

Kling, K. C., Hyde, J. S., Showers, C. J., \& Buswell, B. N. (1999). Gender Differences in Self-Esteem: A Meta-Analysis. Psychological Bulletin, 125, 470-500. https://doi.org/10.1037/0033-2909.125.4.470

Küspert, P., \& Schneider, W. (1998). Würzburger Leise Leseprobe (WLLP): Handanweisung. Göttingen: Hogrefe.

Leflot, G., Onghena, P., \& Colpin, H. (2010). Teacher-Child Interactions: Relations with Children's Self-Concept in Second Grade. Infant and Child Development, 19, 385-405. https://doi.org/10.1002/icd.672

Marsh, H. W. (1986). Negative Item Bias in Ratings Scales for Preadolescent Children: A Cognitive-Developmental Phenomenon. Developmental Psychology, 22, 37-49. https://doi.org/10.1037/0012-1649.22.1.37

Marsh, H. W. (1987). The Factorial Invariance of Responses by Males and Females to a Multidimensional Self-Concept Instrument: Substantive and Methodological Issues. Multivariate Behavioral Research, 22, 457-480. https://doi.org/10.1207/s15327906mbr2204_5

Marsh, H. W. (1989). Age and Sex Effects in Multiple Dimensions of Self-Concept: Preadolescence to Early Adulthood. Journal of Educational Psychology, 81, 417-430. https://doi.org/10.1037/0022-0663.81.3.417

Marsh, H. W. (1990a). Causal Ordering of Academic Self-Concept and Academic Achievement: A Multiwave, Longitudinal Panel Analysis. Journal of Educational Psychology, 82, 646-656. https://doi.org/10.1037/0022-0663.82.4.646

Marsh, H. W. (1990b). A Multidimensional, Hierarchical Model of Self-Concept: Theoretical and Empirical Justification. Educational Psychology Review, 2, 77-172. https://doi.org/10.1007/BF01322177

Marsh, H. W. (1990c). The Structure of Academic Self-Concept: The Marsh/Shavelson Model. Journal of Educational Psychology, 82, 623-636. https://doi.org/10.1037/0022-0663.82.4.623

Marsh, H. W. (1992). The Self-Description Questionnaire (SDQ) I: A Theoretical and Empirical Basis for the Measurement of Multiple Dimensions of Preadolescent SelfConcept: A Test Manual and Research Monograph. Macarthur: University of Western Sydney.

Marsh, H. W., \& Ayotte, V. (2003). Do Multiple Dimensions of Self-Concept Become More Differentiated with Age? The Differential Distinctiveness Hypothesis. Journal of Educational Psychology, 95, 687-706. https://doi.org/10.1037/0022-0663.95.4.687

Marsh, H. W., \& Craven, R. G. (2006). Reciprocal Effects of Self-Concept and Performance from a Multidimensional Perspective: Beyond Seductive Pleasure and Unidimensional Perspectives. Perspectives on Psychological Science, 1, 133-163. https://doi.org/10.1111/j.1745-6916.2006.00010.x

Marsh, H. W., \& Hattie, J. (1996). Theoretical Perspectives on the Structure of Self-Concept. In B. A. Bracken (Ed.), Handbook of Self-Concept (pp. 38-90). New York, NY: Wiley.

Marsh, H. W., \& Hocevar, D. (1985). Application of Confirmatory Factor Analysis to the Study of Self-Concept: First- and Higher-Order Factor Models and Their Invariance across Groups. Psychological Bulletin, 97, 562-582.

https://doi.org/10.1037/0033-2909.97.3.562

Marsh, H. W., \& Martin, A. J. (2011). Academic Self-Concept and Academic Achievement: Relations and Causal Ordering. British Journal of Educational Psychology, 81, 59-77. https://doi.org/10.1348/000709910X503501 
Marsh, H. W., \& O’Mara, A. (2008). Reciprocal Effects between Academic Self-Concept, Self-Esteem, Achievement, and Attainment over Seven Adolescent Years: Unidimensional and Multidimensional Perspectives of Self-Concept. Personality and Social Psychology Bulletin, 34, 542-552. https://doi.org/10.1177/0146167207312313

Marsh, H. W., \& Shavelson, R. (1985). Self-Concept: Its Multifaceted, Hierarchical Structure. Educational Psychologist, 20, 107-123. https://doi.org/10.1207/s15326985ep2003_1

Marsh, H. W., Barnes, J., Cairns, L., \& Tidman, M. (1984). Self-Description Questionnaire: Age and Sex Effects in the Structure and Level of Self-Concept for Preadolescent Children. Journal of Educational Psychology, 76, 940-956. https://doi.org/10.1037/0022-0663.76.5.940

Marsh, H. W., Byrne, B. M., \& Shavelson, R. J. (1988). A Multifaceted Academic Self-Concept: Its Hierarchical Structure and Its Relation to Academic Achievement. Journal of Educational Psychology, 80, 366-380. https://doi.org/10.1037/0022-0663.80.3.366

Marsh, H. W., Byrne, B. M., \& Yeung, A. S. (1999). Causal Ordering of Academic Self-Concept and Achievement: Reanalysis of a Pioneering Study and... Educational Psychologist, 34, 155-167. https://doi.org/10.1207/s15326985ep3403_2

Marsh, H. W., Craven, R. G., \& Debus, R. (1991). Self-Concepts of Young Children 5 to 8 Years of Age: Measurement and Multidimensional Structure. Journal of Educational Psychology, 83, 377-392. https://doi.org/10.1037/0022-0663.83.3.377

Marsh, H. W., Craven, R. G., \& Martin, A. (2013). What Is the Nature of Self-Esteem? Unidimensional and Multidimensional Perspectives. In M. H. Kernis (Ed.), Self-Esteem Issues and Answers: A Sourcebook of Current Perspectives (pp. 16-25). New York, NY: Psychology Press.

Marsh, H. W., Craven, R., \& Debus, R. (1998). Structure, Stability, and Development of Young Children's Self-Concepts: A Multicohort-Multioccasion Study. Child Development, 69, 1030-1053. https://doi.org/10.1111/j.1467-8624.1998.tb06159.x

Marsh, H. W., Ellis, L. A., \& Craven, R. G. (2002). How Do Preschool Children Feel about Themselves? Unraveling Measurement and Multidimensional Self-Concept Structure. Developmental Psychology, 38, 376-393. https://doi.org/10.1037/0012-1649.38.3.376

May, P. (1996). Die Hamburger Schreibprobe. Grundlegende Rechtschreibstrategien erfassen. Grundschule, 28, 17-20.

Mayringer, H., \& Wimmer, H. (2003). SLS 1-4: Salzburger Lese-Screening für die Klassenstufen 1-4. Bern: Huber.

Möller, J., Pohlmann, B., Köller, O., \& Marsh, H. W. (2009). A Meta-Analytic Path Analysis of the Internal/External Frame of Reference Model of Academic Achievement and Academic Self-Concept. Review of Educational Research, 79, 1129-1167. https://doi.org/10.3102/0034654309337522

Neuenschwander, R., Röthlisberger, M., \& Roebers, C. M. (2011). Unterschiede in ausgewählten Bereichen der Schulfähigkeit: ein Vergleich von Kindergarten und einem neuen Schuleingangsmodel in der Schweiz. Psychologie in Erziehung und Unterricht, $58,30-40$.

Nicholls, J. G. (1978). The Development of the Concepts of Effort and Ability, Perception of Academic Attainment, and the Understanding That Difficult Tasks Require More Ability. Child Development, 49, 800-814. https://doi.org/10.2307/1128250

Olsson, U. H., Foss, T., Troye, S. V., \& Howell, R. D. (2000). The Performance of ML, GLS, and WLS Estimation in Structural Equation Modeling under Conditions of Misspecification and Nonnormality. Structural Equation Modeling, 7, 557-595. 
https://doi.org/10.1207/S15328007SEM0704_3

Perren, S. (2007). SOCOMP (Self- and Other-Oriented Social COMPetences). Ein Fragebogen zur Erfassung von selbst-und fremdorientierten verhaltensbezogenen sozialen Kompetenzen. Manual. Zürich: Jacobs Center for Productive Youth Development, Universität Zürich.

Pianta, R. (2001). STRS Student-Teacher Relationship Scale. Professional Manual. Odessa: Psychological Assessment Resources Inc.

Polat, Ö., \& Akşin, E. (2015). A Study of the Relationship between Self-Concept and Primary School Readiness in 60-72 Month-Old Children and the Analysis of Their Primary School Readiness and Self-Concept According to Some Variables. European Journal of Research on Education, 3, 14-21. http://iassr2.org/rs/030202.pdf

Robins, R. W., \& Trzesniewski, K. H. (2005). Self-Esteem Development across the Lifespan. Current Directions in Psychological Science, 14, 158-162. https://doi.org/10.1111/j.0963-7214.2005.00353.x

Roebers, C. M., Cimeli, P., Röthlisberger, M., \& Neuenschwander, R. (2012). Executive Functioning, Metacognition, and Self-Perceived Competence in Elementary School Children: An Explorative Study on Their Interrelations and Their Role for School Achievement. Metacognition and Learning, 7, 151-173. https://doi.org/10.1007/s11409-012-9089-9

Shavelson, R. J., \& Bolus, R. (1982). Self Concept: The Interplay of Theory and Methods. Journal of Educational Psychology, 74, 3-17. https://doi.org/10.1037/0022-0663.74.1.3

Shavelson, R. J., Hubner, J. J., \& Stanton, G. C. (1976). Self-Concept: Validation of Construct Interpretations. Review of Educational Research, 46, 407-441. https://doi.org/10.3102/00346543046003407

Stipek, D., \& Daniels, D. H. (1988). Declining Perceptions of Competence: A Consequence of Changes in the Child or in the Educational Environment? Journal of Educational Psychology, 80, 352-356. https://doi.org/10.1037/0022-0663.80.3.352

Stipek, D., Feiler, R., Daniels, D., \& Milburn, S. (1995). Effects of Different Instructional Approaches on Young Children's Achievement and Motivation. Child Development, 66, 209-223. https://doi.org/10.2307/1131201

Wigfield, A., Eccles, J. S., Yoon, K. S., Harold, R. D., Arbreton, A. J., Freedman-Doan, C., \& Blumenfeld, P. C. (1997). Change in Children's Competence Beliefs and Subjective Task Values across the Elementary School Years: A 3-Year Study. Journal of Educational Psychology, 89, 451-469. https://doi.org/10.1037/0022-0663.89.3.451

Wilgenbusch, T., \& Merrell, K. W. (1999). Gender Differences in Self-Concept among Children and Adolescents: A Meta-Analysis of Multidimensional Studies. School Psychology Quarterly, 14, 101-120. https://doi.org/10.1037/h0089000

Wylie, R. C. (1989). Measures of Self-Concept. Lincoln: University of Nebraska Press. 